\title{
Local approach studies of the effect of load history on ductile fracture
}

DOI:

10.1115/PVP2008-61371

Link to publication record in Manchester Research Explorer

\section{Citation for published version (APA):}

Howells, R. O., Jivkov, A. P., Beardsmore, D. W., Sharples, J. K., \& Watson, C. T. (2008). Local approach studies of the effect of load history on ductile fracture. In American Society of Mechanical Engineers, Pressure Vessels and Piping Division (Publication) PVP/ASME Pressure Vessels Piping Div. Publ. PVP (Vol. 6, pp. 1003-1011). American Society of Mechanical Engineers. https://doi.org/10.1115/PVP2008-61371

\section{Published in:}

American Society of Mechanical Engineers, Pressure Vessels and Piping Division (Publication) PVP|ASME Pressure Vessels Piping Div. Publ. PVP

\section{Citing this paper}

Please note that where the full-text provided on Manchester Research Explorer is the Author Accepted Manuscript or Proof version this may differ from the final Published version. If citing, it is advised that you check and use the publisher's definitive version.

\section{General rights}

Copyright and moral rights for the publications made accessible in the Research Explorer are retained by the authors and/or other copyright owners and it is a condition of accessing publications that users recognise and abide by the legal requirements associated with these rights.

\section{Takedown policy}

If you believe that this document breaches copyright please refer to the University of Manchester's Takedown Procedures [http://man.ac.uk/04Y6Bo] or contact uml.scholarlycommunications@manchester.ac.uk providing relevant details, so we can investigate your claim.

\section{OPEN ACCESS}




\title{
LOCAL APPROACH STUDIES OF THE EFFECT OF LOAD HISTORY ON DUCTILE FRACTURE
}

\author{
R O Howells, A P Jivkov, D W Beardsmore, J K Sharples \\ Serco Technical and Assurance Services, Birchwood Park, Warrington, Cheshire, WA3 6GA, UK \\ M R Goldthorpe \\ University of Manchester, Sackville Street, Manchester, M60 1QD, UK \\ C T Watson \\ Rolls-Royce plc, Derby, PO Box 2000, DE21 7XX, UK
}

\begin{abstract}
Local Approach methods provide alternative routes for carrying out fracture mechanics assessments. These methods use a finite element analysis of the cracked component that incorporates a micro-mechanical model of material behaviour in the region of the crack tip. The development of damage, and eventual failure of the material for particular loading conditions, is calculated directly by the micro-mechanical model. A potential advantage of such models is that they can automatically incorporate the effects of loss of constraint and load history.
\end{abstract}

This paper describes studies that compare the predictions of the Gurson-Tvergaard-Needleman (GTN) [1,2,3] local approach model of ductile fracture with traditional fracture mechanics parameters. The model is used to consider the effect of load history on ductile fracture initiation in a typical fracture mechanics test specimen (CT). The aim is to investigate the benefits of applying such models to situations where events in the plant loading history can have a significant effect on crack driving force for typical defects that subsequently develop during service. It is anticipated that the results will be used to make improvements to the accuracy of the traditional assessment procedures.

The results show that in certain circumstances, for instance where residual stresses are present in the vicinity of a defect, load excursions on the specimen can have a beneficial effect on global load carrying capacity and that load history effects can be captured by adopting the local approach for the assessment of ductile fracture. It is also noted that the trends observed in other local parameters, e.g. $J$ and CTOD, must be treated with caution, probably due to near crack-tip softening associated with the implementation of the GTN model in a region of high stress concentration.

\section{INTRODUCTION}

Traditional fracture mechanics assessments of defects in structures compare $\mathbf{J}$ crack driving force with lower bound estimates of fracture toughness obtained on deeply-cracked, high constraint, fracture toughness specimens such as the compact tension and three-point bend geometries. The crack driving force can be obtained by finite element analysis using appropriate elastic-plastic material properties. For simple defect geometries, with well established elastic stress intensity factor solutions, the R6 [4] procedure can be used to estimate a conservative value of the crack driving force by means of an appropriate failure assessment curve. Such procedures usually give upper bound estimates of crack driving force. As a result, the safety margins are usually under-estimated.

Typical defects in actual vessels and pipework are often shallow and located in predominantly uniform stress fields. The resulting plastic constraint at the tip of the defect is therefore lower than experienced by the pre-crack in the fracture toughness test specimen. This leads to a higher level of apparent fracture toughness than measured by the traditional test specimen. However, this can be accounted for in assessments by using a material toughness obtained on a test specimen that matches the crack tip constraint of the defect in the structure, by elevating the material's toughness, or by decreasing the calculated crack tip driving force.

Local Approach methods provide an alternative approach of carrying out a fracture mechanics assessment. These methods use a finite element model of the defect, incorporating a micro-mechanical model for the materials fracture behaviour ahead of the crack tip, which is the so-called fracture process zone. The susceptibility of the material to fracture for given load conditions is calculated directly from the micromechanical model either as a yes/no instruction (for Ductile fracture models), or as a probability value (for Cleavage fracture models). One possible advantage of the use of such models is that they may 
incorporate loss of constraint and load history effects automatically. Several different local approach models have been suggested by various researchers, but the most widely promoted and used models are the Gurson-Tvergaard-Needleman (GTN) ductility model [1-3], and the Beremin cleavage model [5]. R6 also provides guidance on the use of a simpler ductile model, the Beremin ductile model [6], which is based on the Rice and Tracey description of ductile failure [7]. These models contain a number of material dependent (and possibly temperature-dependent) parameters or constants that must be correctly defined to give meaningful predictions. Previous attempts to tune the Gurson-Tvergaard-Needleman ductile model have proved problematic and have hampered efforts to apply the local approach to problems of relevance. Here, typical model parameters have been selected to represent ductile material in order to avoid such difficulties and facilitate an investigation of the problem of interest.

The work presented focuses on application of the GTN model to an enlarged CT specimen geometry, described in the next section. Various load history cases are considered, ranging from a base case with no load history, to cases containing crack opening residual stress fields and subject to various tensile 'overloads' representative of the occasional excursions from normal operating loads associated with some plant. The methodology for implementing these histories in the model is described, along with detail of the load histories themselves. Finally, the local approach model is used to characterise crack-tip damage for each case, and an attempt is made to use the GTN damage parameter to quantify the effect of load history on susceptibility to ductile fracture initiation. The local damage parameter is the void volume fraction, $f$, for the Gurson-Tvergaard-Needleman model. An attempt is made to relate the critical damage parameter to the initiation fracture toughness, $J_{\mathrm{c}}$, for particular load history cases.

\section{FINITE ELEMENT ANALYSIS}

\section{Geometry and finite element mesh}

An enlarged (x8) compact tension specimen (Figure 1) was considered with a wide notch that allowed for the introduction of residual stresses via an initial compressive load. Figure 2 shows the near notch and crack tip regions. A two dimensional plane strain finite element model of the specimen was developed. Due to symmetry with respect to the crack plane only half of the specimen was modelled. Scoping calculations found that the enlargement of the specimen was necessary to maintain contained plasticity conditions (small scale yielding), and thus maintain constraint, during tensile loading for crack driving forces up to the expected fracture toughness of the material studied. The requirement to maintain constraint stemmed from a desire to ensure that valid $J$ values could be calculated for each case.

The coordinate system, introduced in Figure 2, is centred at the crack tip. Thus, the symmetry plane consists of the crack flank in the region $(-20 \leq X \leq 0)$ and crack front in the region $(0 \leq X \leq 200)$. The mesh in the vicinity of the crack tip consists of $16 \times 8$ square elements of size $0.125 \mathrm{~mm}$, and this rectangular region is centred at the tip. The commercial finite element code ABAQUS [8] was used for the analysis. Eight-node plane strain finite elements with quadratic interpolation and reduced integration are used throughout the model.

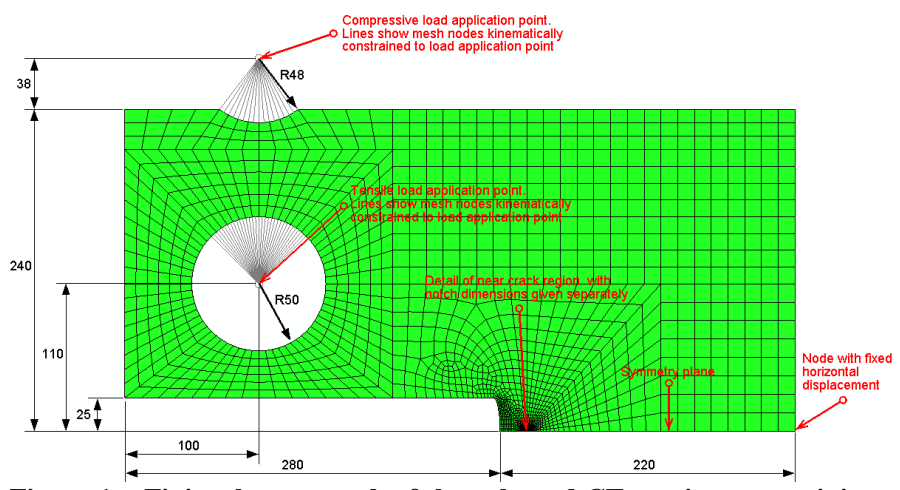

Figure 1 - Finite element mesh of the enlarged CT specimen containing a wide notch (half model due to symmetry)

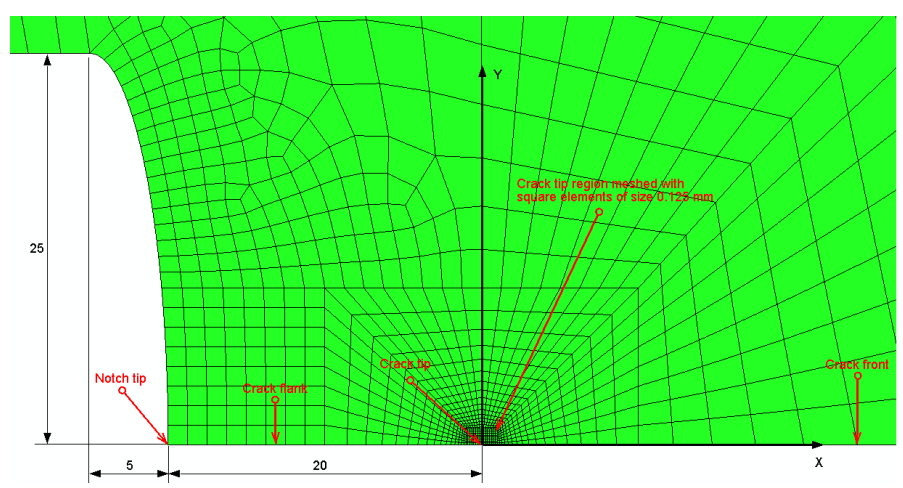

Figure 2 - Expanded view of the FE mesh geometry near the notch and crack tips

\section{Material Properties}

Weld material of grade 316 stainless steel is considered. The mechanical behaviour of this material at room temperature is characterized by a Young's modulus $E=171 \mathrm{GPa}$, Poisson's ratio $v=0.294$ and tabular data relating stress to plastic strain from uniaxial tensile tests at room temperature. The relation stress-plastic strain is shown in Figure 3. Note that the yield stress defined as the stress at $0.2 \%$ plastic strain is denoted by $\sigma_{0}$ and is used in the work as a normalising parameter for stresses calculated in the analyses.

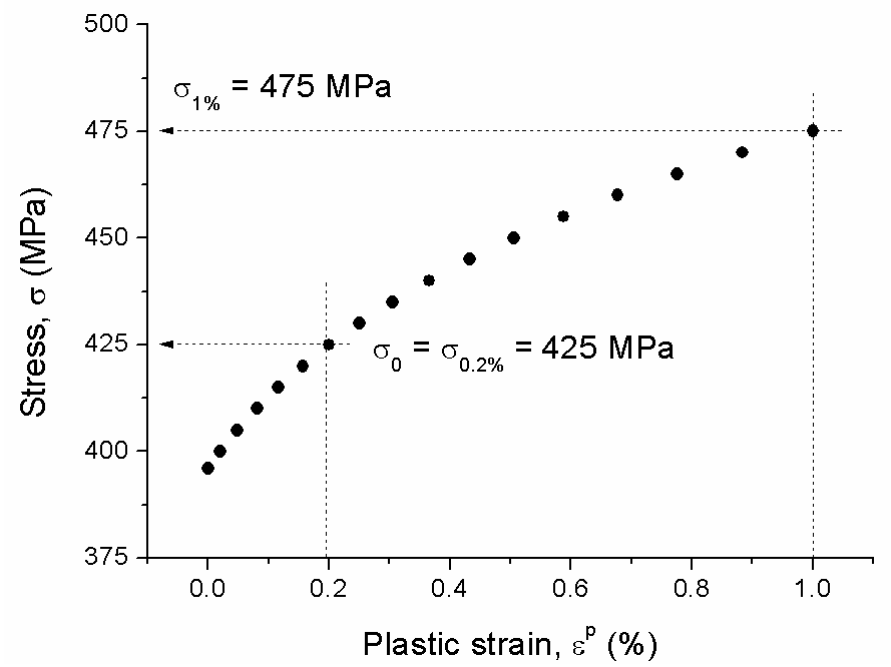

Figure 3 - Stress vs. plastic strain curve for 316 stainless steel weld material 


\section{Micro-mechanical Material Models}

The GTN [1-3] model has been implemented in the analyses. The following standard definitions were used in describing the model. With $\sigma_{i j}$ denoting the components of the Cauchy stress tensor, the mean stress (first stress invariant) is given by:

$$
\sigma_{m}=\frac{1}{3} \sigma_{i i}
$$

where summation over repeated indices is understood, and the equivalent stress (second stress invariant or von Mises stress) is given by:

$$
\sigma_{e q}=\sqrt{\frac{3}{2} S_{i j} S_{i j}}
$$

where $S_{i j}=\sigma_{i j}-\sigma_{m} \delta_{i j}$ are the components of the deviatoric stress tensor ( $\delta_{i j}$ are the components of the identity tensor). With $\varepsilon_{i j}^{p}$ denoting the components of the plastic strain tensor, the mean plastic strain is given by:

$$
\varepsilon_{m}^{p}=\frac{1}{3} \varepsilon_{i j}^{p}
$$

and the equivalent plastic strain is given by:

$$
\varepsilon_{e q}^{p}=\sqrt{\frac{2}{3} \varepsilon_{i j}^{p} \varepsilon_{i j}^{p}}
$$

Equations (3) and (4) may be written in rate form, with dotted strain components, to become expressions for the mean plastic strain rate and the equivalent plastic strain rate, respectively.

\section{Gurson-Tvergaard-Needleman model}

The Gurson-Tvergaard-Needleman (GTN) constitutive model [1-3] is an elastic-plastic continuous model that aims to account for the ductile rupture mechanisms of nucleation, growth and coalescence of micro-voids via accumulation of ductile damage. The model is essentially a pressure-dependent plasticity model of the class used to model porous materials. The material response depends not only on the deviatoric stresses as in standard plasticity, but also on the development of the hydrostatic stress. Damage accumulation is modelled by introduction of two continuous internal state variables. The first one is the void volume fraction, denoted by $f$, which represents the micro-voids distributed continuously throughout the material matrix. This variable is a measure of local material damage. The second variable is the equivalent plastic strain of the fully dense matrix, which is a microscopic parameter evolving according to [9]:

$$
\dot{\varepsilon}_{e q(M)}^{p}=\frac{\sigma_{e q} \dot{\varepsilon}_{e q}^{p}+3 \sigma_{m} \dot{\varepsilon}_{m}^{p}}{(1-f) \sigma_{0}}
$$

In Equation $5, \sigma_{0}$ is the flow stress of the fully dense matrix, whose relation to the equivalent plastic strain of the fully dense matrix should be prescribed as material input data. The relation between the flow stress and equivalent plastic strain of the fully dense matrix in this work is input to the model in tabular form using the data shown in Figure 3. The evolution of the void volume fraction includes contributions from the nucleation of new micro-voids and the growth of existing micro-voids [10]

$$
\dot{f}=\dot{f}_{\text {nucl }}+\dot{f}_{\text {grow }}
$$

The void volume rate due to nucleation of new micro-voids is defined by:

$$
\dot{f}_{n u c l}=A \dot{\varepsilon}_{e q(M)}^{p}
$$

where $A$ is a function of the equivalent plastic strain of the fully dense matrix, selected such that the nucleation strain obeys a normal distribution with mean value $\varepsilon_{N}$ and standard deviation $S_{N}$ :

$$
A=\frac{f_{N}}{S_{N} \sqrt{2 \pi}} \exp \left[-\frac{1}{2}\left(\frac{\varepsilon_{e q(M)}^{p}-\varepsilon_{N}}{S_{N}}\right)^{2}\right]
$$

with $f_{N}$ denoting the volume fraction of void nucleating particles. The void volume rate due to growth of existing micro-voids is defined by

$$
\dot{f}_{\text {grow }}=3(1-f) \dot{\varepsilon}_{m}^{p}
$$

The coalescence of micro-voids is represented by including accelerated softening in the expression for the yield surface via a modified void volume fraction, $f^{*}$. The yield function $\Phi$ is isotropic and identical to the plastic potential $g$ in this model. The expression is given by:

$\Phi=g=\left(\frac{\sigma_{e q}}{\sigma_{0}}\right)^{2}+2 q_{1} f^{*} \cosh \left(\frac{3 q_{2} \sigma_{m}}{2 \sigma_{0}}\right)-\left(1+q_{3} f^{* 2}\right)=0$

where $q_{1}, q_{2}, q_{3}$ are material constants and $\sigma_{0}$ is the flow stress of the fully dense matrix.

The modified void volume fraction is related to the physical one in the following way. At low values of void volume fraction, $f^{*}=f$, but above some critical void volume fraction $f_{c}$ the value of $f^{*}$ increases more rapidly to give increased softening as the micro-voids coalesce. Fracture occurs at another level of the void volume fraction, denoted by $f_{f}$, when the local load carrying capacity is reduced to zero. This behaviour is represented by the relation [9]

$$
f^{*}=\left\{\begin{array}{cl}
f, & f \leq f_{c} \\
f_{c}+\left(\frac{f_{u}^{*}-f_{c}}{f_{f}-f_{c}}\right)\left(f-f_{c}\right), & f_{c}<f<f_{f} \\
f_{u}^{*}, & f \geq f_{f}
\end{array}\right.
$$

where $f^{*}{ }_{u}$ is the value of $f^{*}$ at zero stress, i.e. when $f$ reaches $f_{f}$. This constant is calculated from Equation 10 for given material constants $q_{1}, q_{2}, q_{3}$ and zero stresses.

In summary, the GTN model constitutes an elastic-plastic response determined from the yield surface and the plastic potential, Equation 10 and Equation 11, and evolution of two internal state variables given by Equation 5 to Equation 9. The model is implemented in a user-defined procedure, UMAT, for Abaqus [11]. The parameters of the model selected for this work are summarized in Table 1. 


\begin{tabular}{lllllllll}
\hline$f_{0}$ & $f_{c}$ & $f_{f}$ & $f_{N}$ & $\varepsilon_{N}$ & $S_{N}$ & $q_{1}$ & $q_{2}$ & $q_{3}$ \\
\hline \hline 0.00072 & 0.15 & 0.60 & 0.01 & 0.3 & 0.1 & 1.5 & 1 & 2.25
\end{tabular}

Table 1- GTN Model Parameters

With these parameters, the limit value of the modified void volume fraction becomes $f^{*}{ }_{u}=2 / 3$, see Equation 10 . Further the initial equivalent plastic strain of the fully dense matrix is zero.

\section{LOAD HISTORY CASES}

Five load histories have been considered by means of altering the load line displacement history (the analyses were conducted in displacement control). Case 1 was a base case, where the crack was introduced to the position shown in Figure 2 before application of a tensile load. In Cases 2 through 5, residual stresses were introduced via application and release of a compressive load to the wide notched model without a crack. In Case 2 the crack is then introduced and the model is subject to tensile loading. In Cases 3 through 5 additional tensile load (the so called "overload") and release steps are applied after the introduction of residual stress and before the introduction of the crack and primary tensile loading. The five load histories are shown as a function of applied displacement at the specimen load line in Figure 4, Figure 5 and Figure 6.

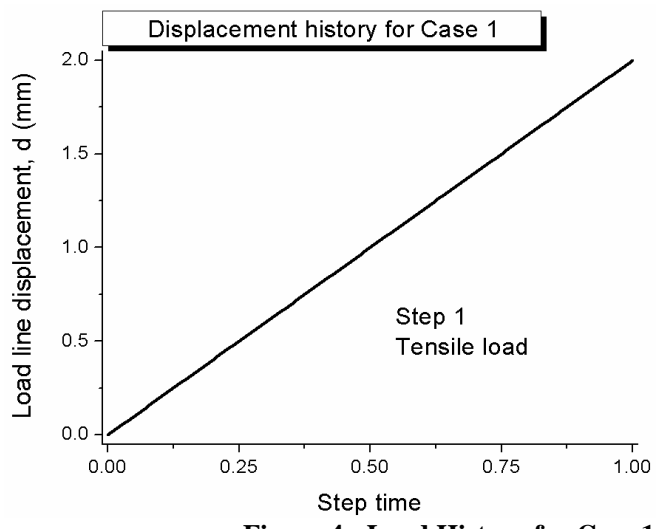

Figure 4 - Load History for Case 1

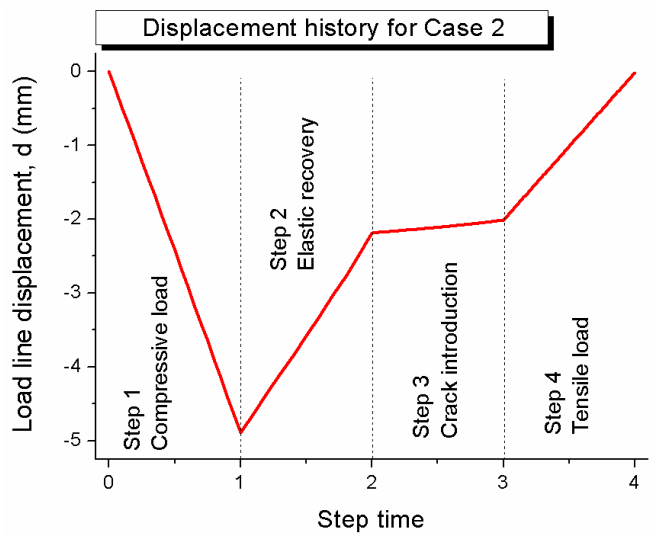

Figure 5 - Load History for Case 2

\section{Residual Stress Profiles}

The residual stresses were introduced to the region ahead of the notch via a two-step simulation. First a compressive stress field was generated ahead of the notch through the application of a negative displacement at the load line $(-5 \mathrm{~mm}$, see Figure 5 and Figure 6$)$. The compressive load application point was then released to allow for the elastic recovery of the model and the creation of tensile residual stresses ahead of the notch. Figure 7 shows the stress profile generated for all cases prior to the introduction of any other load history i.e. overloads. Note that the stress is normalised by the yield stress and that near yield levels of residual stress were observed at the crack tip position.

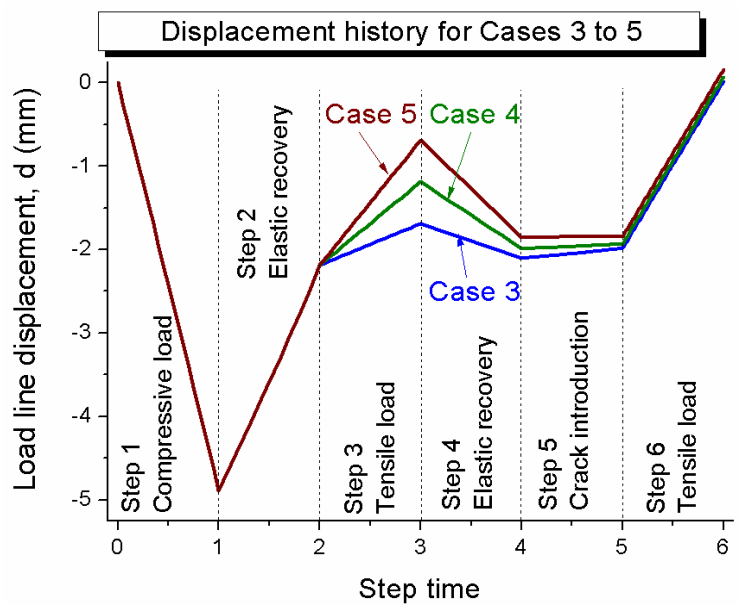

Figure 6 - Load Histories for Cases 3-5

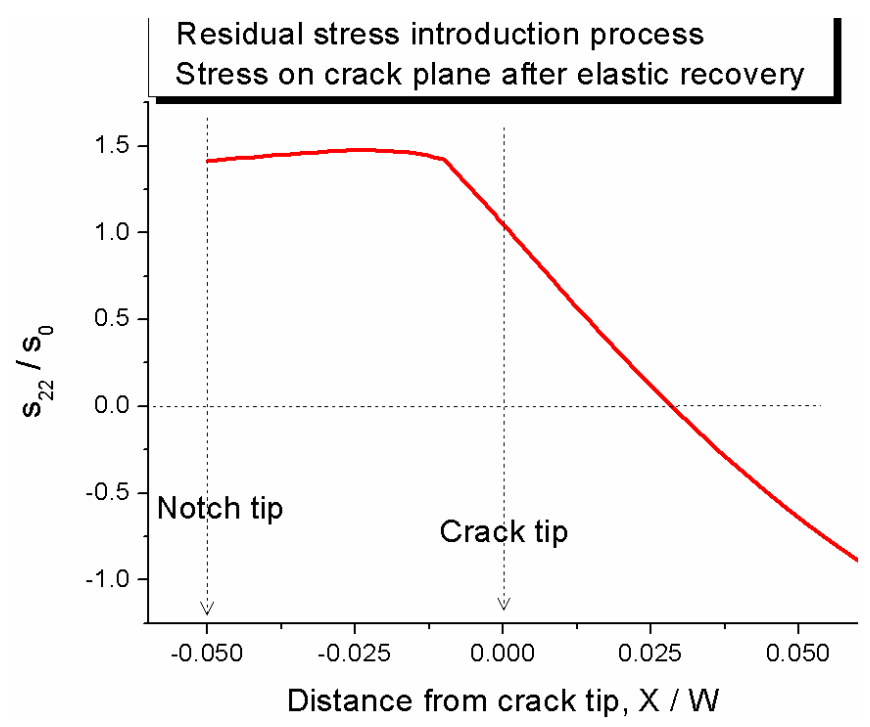

Figure 7 - Residual stress profile for Case 2-5, prior to overload and crack introduction

\section{Overload process}

In a similar way to the residual stress introduction process, the overloads were applied via two simulation steps. First a tensile load is applied via prescribed vertical displacement of the tensile load application point (Figure 1). This displacement increases from 0 to $d_{p}$ $\mathrm{mm}$, relative to the position at the beginning of the step, where $d_{p}$ differentiates the load history Cases 3 to 5 with $d_{p}=0.5 \mathrm{~mm}$ in Case 3 , $d_{p}=1.0 \mathrm{~mm}$ in Case 4 , and $d_{p}=1.5 \mathrm{~mm}$ in Case 5 . The tensile load application point was then released allowing for the elastic recovery of the model. The load versus load line displacement curves for the overload process are shown in Figure 8. Figure 9 shows the effect of 


\section{DRAFT}

tensile overloads on the residual stress field ahead of the notch i.e. in the vicinity of the future crack tip, compared to the case of no overload (Case 2). There is a progressive reduction in tensile residual stress levels along the crack flanks and at the crack tip from Case 3 through Case 5 in accordance with increasing level of overload (Figure 8), with Case 5 resulting in compressive stresses near the notch tip.

\section{Crack Introduction}

Figure 10 shows the effect of stress redistribution, resulting from the introduction of the crack, on the residual stress fields ahead of the crack tip position. There are clearly significant crack opening stresses generated, with the highest stresses observed for Case 2 and a progressive reduction with increasing overload from Case 3 through 5.

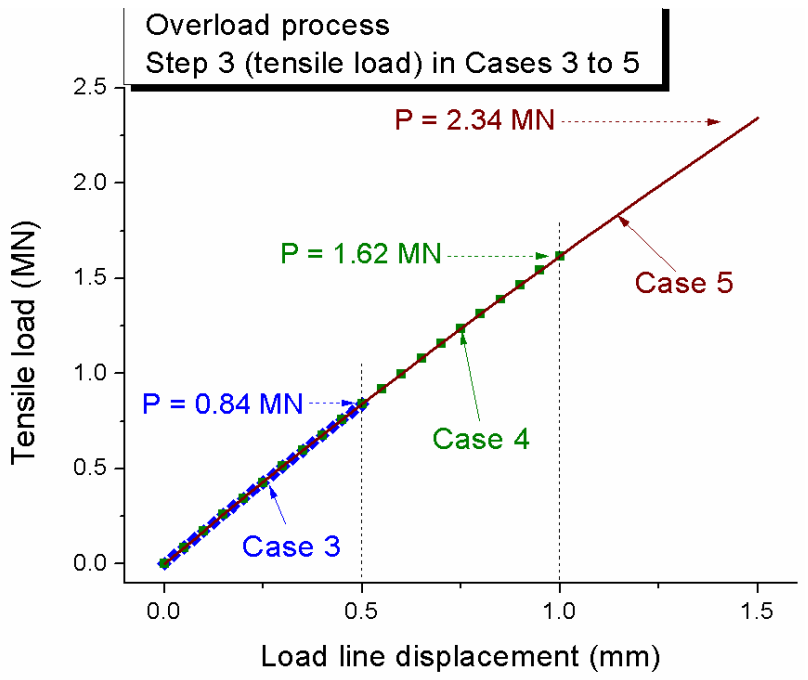

Figure 8 - Load versus load line displacement traces for overload steps in Cases 3-5

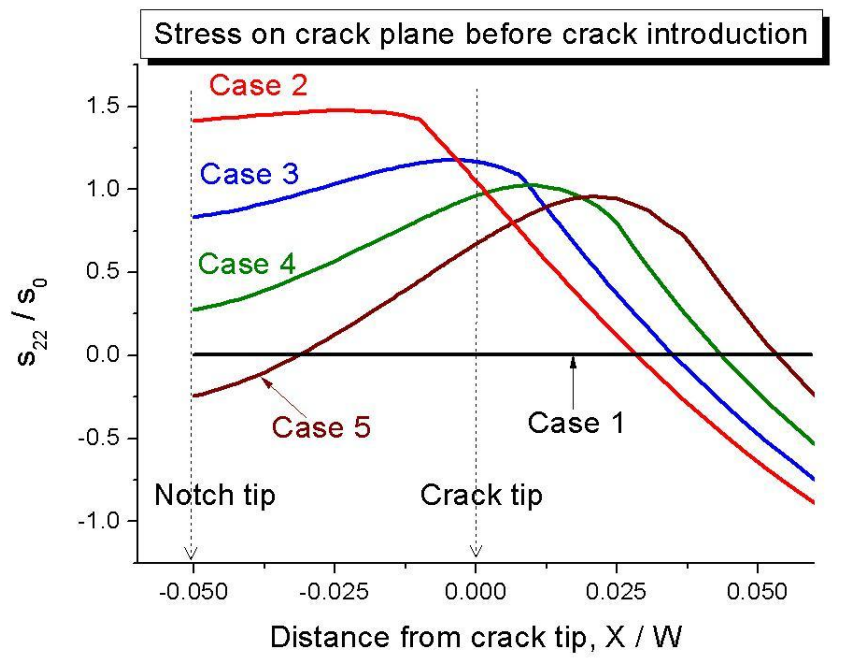

Figure 9 - Residual stress profiles for Cases 3-5 prior to crack introduction

\section{Tensile loading of the cracked specimen}

A global tensile crack opening stress was applied to the model in all cases in order to establish trends in the material behaviour as a function of load history. The load was applied via prescribed vertical displacement of the tensile load application point from 0 to 2 $\mathrm{mm}$, relative to the position at the beginning of the step. The following sections describe how changes in the load history from case to case affect the response of the material to this final tensile load, which is equivalent to fracture testing a CT specimen in tension.

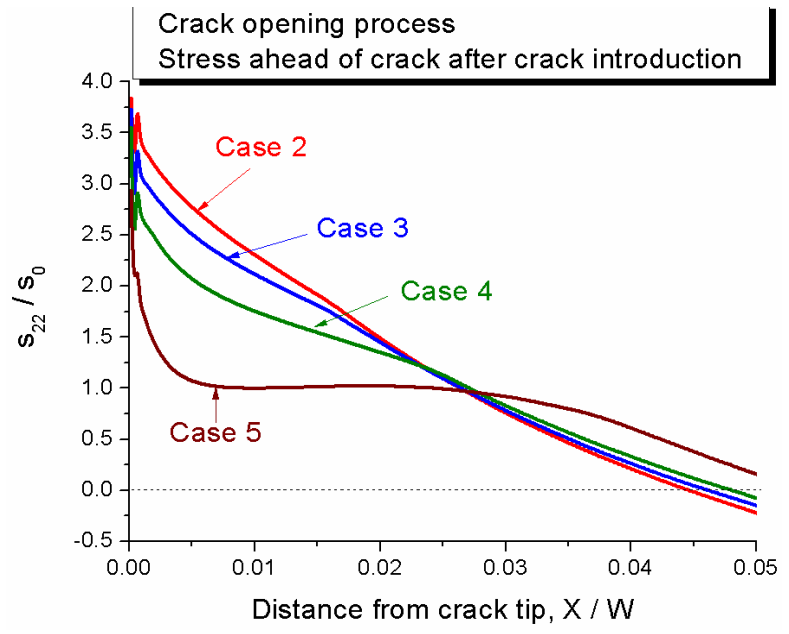

Figure 10 - Residual stress profiles ahead of the crack tip after the crack introduction step

\section{CHARACTERISATION OF CRACK TIP CONDITIONS}

For the models considered it was possible to monitor a number of fracture parameters, namely; the local damage parameter $(f)$, the $J$-integral and crack-tip opening displacement (CTOD), and load line displacement and load. These provide a means of assessing the response of the structure local to the crack tip (damage parameters, $J$, CTOD) and the global response (load and displacement at the load line).

\section{Determination of damage parameters}

The Local Approach parameter, $f$, was used to quantify the events within the fracture process zone. This parameter was monitored and recorded at the four integration points of the process zone element. The maximum value of the void volume fraction during the crack opening process was found at the integration point closest to the crack tip. The fracture process zone was assumed to be confined to the first element ahead of the crack tip, which has a size of $125 \mu \mathrm{m}$.

\section{Determination of $\mathbf{J}$ and CTOD}

The crack driving force is represented by the $J$-integral. The $J$-integral was originally derived as a line integral on contours surrounding a singularity in non-linear elastic materials [12]. It represents the energy flux from the exterior of the contour towards the singularity and in case of cracks is interpreted as energy release rate per unit crack advance. In all cases presented here, the $J$ integral calculated during the $\mathrm{FE}$ analyses was determined using an extension of the $J$ formulation commonly applied in ABAQUS [8], because in cases of non-proportional loading, and initial plastic or thermal strains, additional terms have to be added to the original expression for the energy flux $[13,14]$. In all load history cases studied in this work with the GTN material model the vicinity of the crack tip is in a state of non-proportional loading. This is because the damage accumulation redistributes stresses and strains in the vicinity of the crack tip, resulting in a non-proportional increment of these fields. The process of residual stress introduction and overload in load history Cases 2 to 5 accumulate initial plastic strains prior to crack opening. Hence, in 
all cases studied, an extended form of the $J$-integral must be used to properly calculate the flux of energy towards the crack tip. Such an extended expression for the energy flux, developed in terms of equivalent domain integral [15], has been used in this work. The calculations of the crack driving force are performed with a postprocessing programme (JEDI) [15] assuming non-proportional loading for all load history cases and initial plastic strains where present.

A further standard near tip parameter in fracture mechanics is the crack tip opening displacement, defined as the normal displacement of the point where a $45^{\circ}$-line from the crack tip intersects the crack flank. To facilitate comparison between different load history cases, this standard parameter is not used. Instead, the displacement normal to the crack plane of the point at distance $250 \mu \mathrm{m}$ behind the tip has been monitored and recorded. This is referred to as crack opening displacement in the presentation of the results.

\section{EFFECTS OF LOAD HISTORY ON DUCTILE FRACTURE}

The following sections primarily aim to describe the trends in the effect of load history on susceptibility to ductile fracture initiation, as determined from the GTN damage mechanics models. Further, the implications for the load bearing capacity of the specimen are considered, as this is what would be observed in equivalent fracture tests.

\section{Fracture Initiation Criterion}

Fracture initiation was assumed when the void volume fraction at the integration point closest to the crack tip reached the critical value of $f_{c}=0.15$.

\section{Effect of crack introduction on ductile damage}

Figure 11 plots the GTN damage parameter, $f$, as a function of the load line deflection attributable to crack opening residual stresses during the crack introduction process. Subscripts 4 and 5 denote damage parameter values at the end of step 4 and step 5 of the load history, respectively. There is clearly an effect of the residual stress introduction process on the amount of damage and the damage parameter exhibited a reduction of $f$ from $f_{0}=0.00072$ (the characteristic initial value for the material) in all cases (except Case 1). This is an artefact of the compression step necessary to introduce the tensile residual stress field into the region ahead of the notch where compressive plastic strains were generated during the loading process. In Cases 3-5, the subsequent tensile overload generates tensile plastic strains ahead of the notch, resulting in an increase in $f$ relative to the value for Case 2 at the end of the residual stress introduction process. It can be argued that the residual stress introduction process is 'artificial' in comparison to a real test piece and hence $f_{0}$ should not drop below 0.00072 prior to crack introduction. In addition, the subsequent overloads applied to Cases 3-5 resulted in an increase in $f$, relative to the new value at the end of the residual stress introduction.

These variations in $f$ prior to the final tensile loading step were small, especially when compared to the differences in $f$ generated by introducing the crack into the various residual stress fields considered. However, to test the potential impact of this effect, some simulations were performed with the GTN model switched off during this process for Cases 2 to 5 . This was achieved by considering the material to be elastic-plastic with isotropic hardening during the residual stress introduction process. After completion of the process, the void volume fraction was set to its initial value, $f_{0}=0.00072$, and the simulations continued with the standard GTN model. These simulations showed that the variations of the void volume fraction at the onset of crack introduction had an insignificant effect on the results for global loads and crack driving forces in the subsequent processes. For this reason, and due to time constraints, these further analyses are not presented in this paper, however subsequent work in this area needs to consider the implications of residual stress introduction on the damage mechanics parameter at the start of final tensile loading.

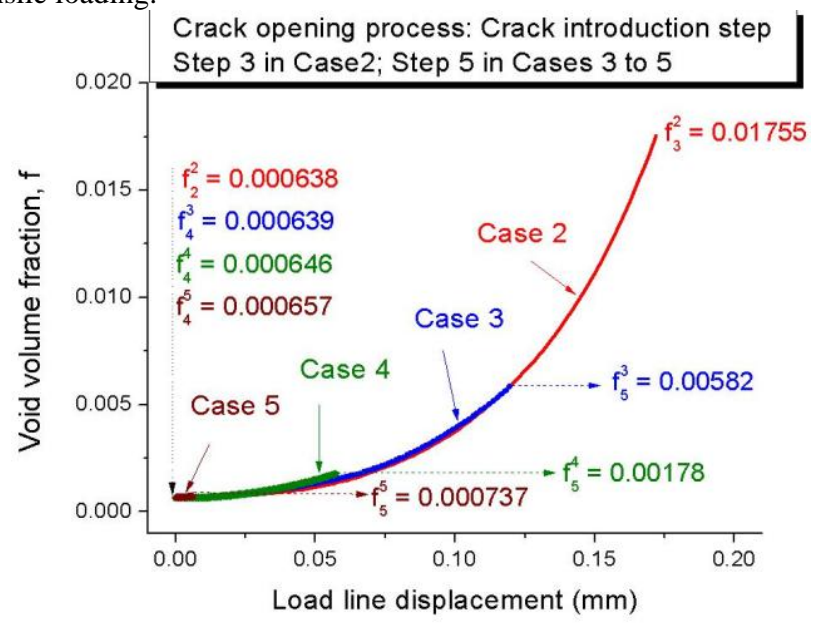

Figure 11 - GTN damage parameter evolution during crack introduction

\section{Assessment of susceptibility to ductile fracture initiation}

Figure 11 shows the extent of ductile damage attributable to crack opening residual stresses at the end of the crack introduction process, i.e. prior to the final tensile loading step to initiation. As the failure criterion, $f_{\mathrm{c}}=0.15$, is considered to be the point of ductile fracture initiation, it is clear that prior to final tensile loading the margin to failure of each case rank as follows; Case $1>$ Case $5>$ Case $4>$ Case $3>$ Case 2. This observation is borne out by Figure 12 which demonstrates the global load on the specimen at $f_{\mathrm{c}}$ for each case. This result is not unexpected when the residual stress fields acting on the crack are considered (Figure 9 and Figure 10), which are the result of the load history. In this particular case there is a clear benefit to the global behaviour of the specimen of tensile overloads prior to crack introduction that generate sufficient plasticity ahead of the notch tip to modify the residual stress field upon elastic recovery.

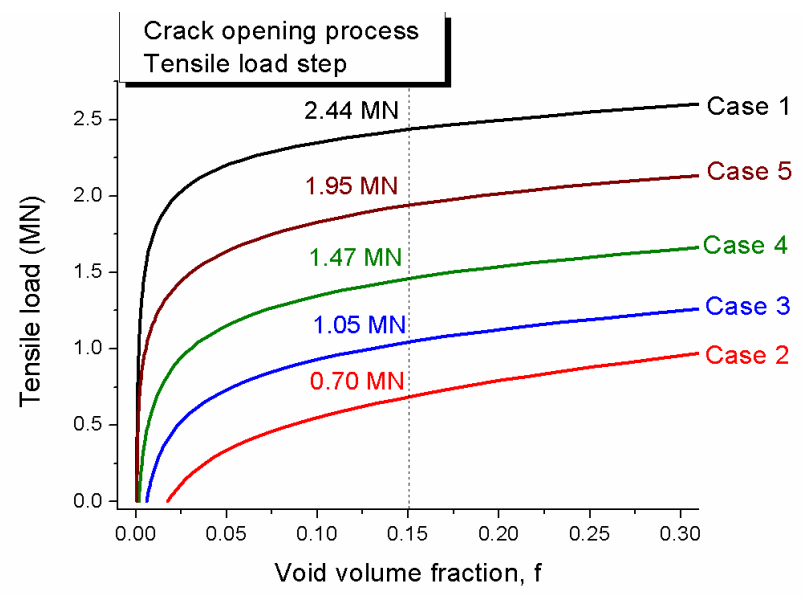

Figure 12 - Variation of tensile load carrying capacity at $f_{\mathrm{c}}$ as a function of load history 


\section{Trends in global crack driving force}

The global load-displacement behaviour of the modelled specimens is shown in Figure 13, along with a curve demonstrating the variation of load carrying capacity at a fixed $f=f_{\mathrm{c}}$. From the same plot it is possible to invoke the ASTM-E1820-06 testing procedure [16] to calculate 'global' or far-field $J$-fracture toughness values from the load displacement traces up to the load at $f=f_{c}$. The results of this analysis are shown in Figure 14. For Case 1, the calculated fracture toughness agrees well with the mean fracture toughness for Type 316 stainless steel weld metal given in R66, which is $193 \mathrm{~kJ} / \mathrm{m}^{2}$ [17]. As expected from the load-displacement behaviour, the apparent toughness in each case scales with the magnitude of the crack opening residual stresses that exist prior to final tensile loading.

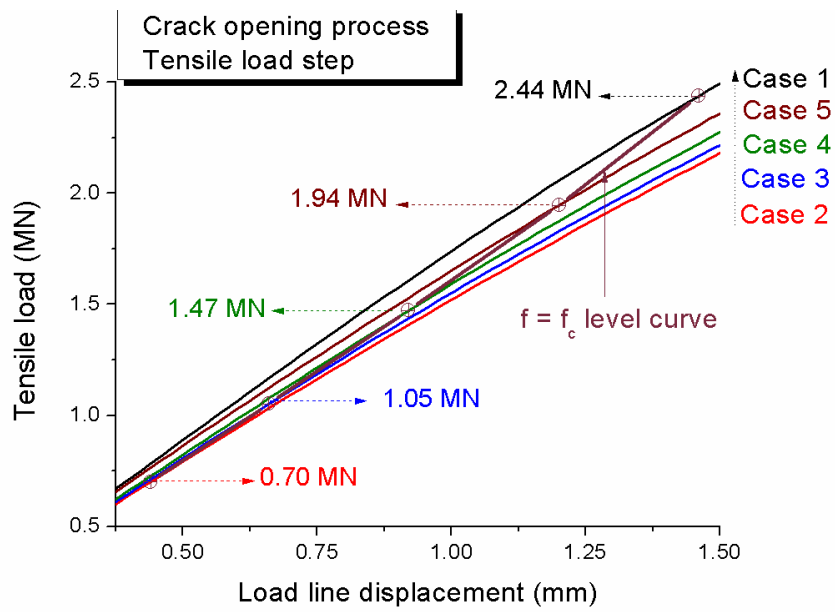

Figure 13 - Tensile load as a function of load line displacement

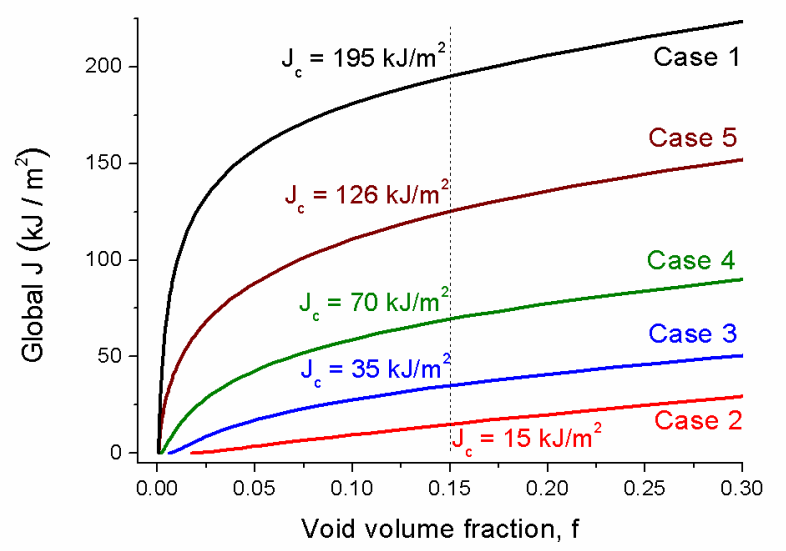

Figure 14 - 'Global' $\mathrm{J}$, crack driving force, as a function of ductile damage. J values were determined in line with the ASTM-E1820-06 [16] testing procedure from load vs. load line displacement plots (Figure 13)

\section{Trends in J-crack driving force and CTOD at the crack tip}

Whilst is was possible to calculate $\mathbf{J}$ values analogous to those calculated in real tests (above), near-field $J$ values were also calculated by JEDI for each case. The results are shown in Figure 15 as a function of $f$ in the vicinity of $f_{\mathrm{c}}$. The trends exhibited are clearly at odds with the globally observed behaviour. There is apparently no change in crack driving force at initiation between Case 1 and Case 2, and Cases 3-5 suggest increased $J_{\mathrm{c}}$ values as a result of the tensile overload prior to crack introduction.

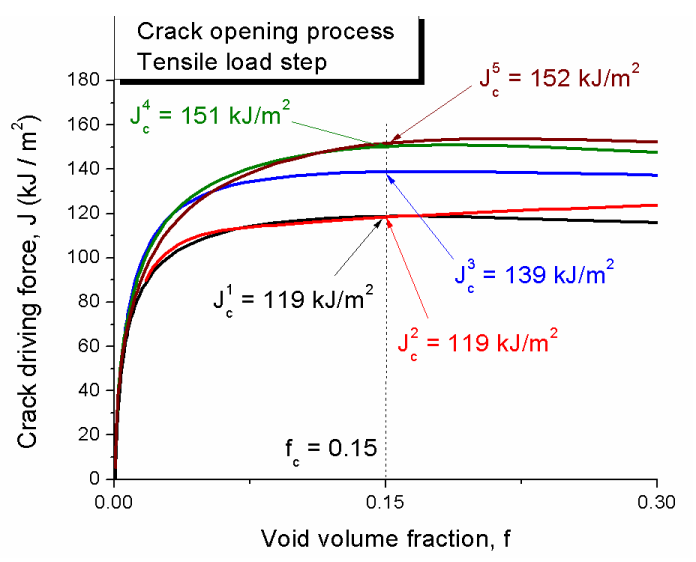

Figure 15 - J, crack driving force as a function of GTN void volume fraction

When CTOD is used as the crack-tip characterising parameter (Figure 16), there is a significant increase in apparent critical CTOD between Case 1 and Case 2 that taken at face value suggest a benefit to local fracture toughness of the tensile residual stress field. The trends for Cases 3-5 are similar to those observed for near-field $J$ values (Figure 15). Qualitatively, neither the trend in near field $J$, nor CTOD are in any way amenable to the same explanation as the global $J$ trends, in terms of the magnitude of the residual stresses in the vicinity of the crack. These observations imply that in the cases considered here, neither local $J$ nor CTOD values are adequate indicators of global behaviour.

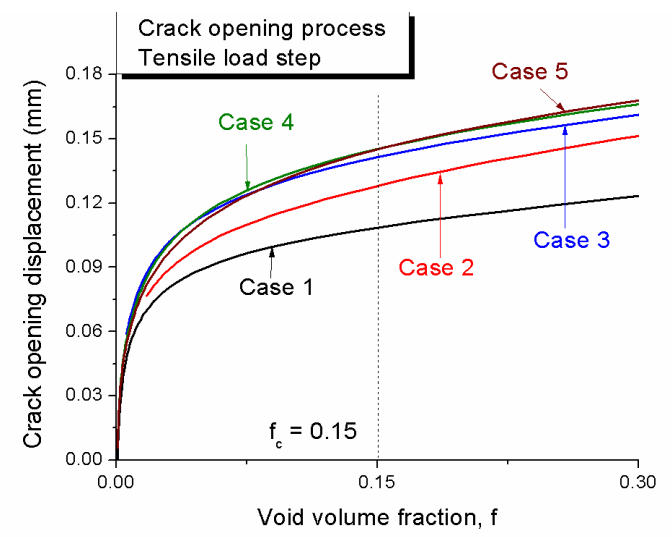

Figure 16 - CTOD development as a function of void volume fraction

Figure 17 shows the distribution of stresses ahead of the crack tip at the critical $J$ value, which do not conform to the classic HRR-field representation. This is most likely due to the material softening effect that is inherent to the GTN model in highly damaged regions, in this case the material immediately ahead of the crack tip. As can be seen in the figure, this limits the stresses immediately ahead of the crack, and results in redistribution of the stresses in regions further away from the crack tip. This is further evidence that near field $J$, (or energy flux towards the crack), cannot be used in these particular cases as an indicator of fracture toughness. 


\section{DRAFT}

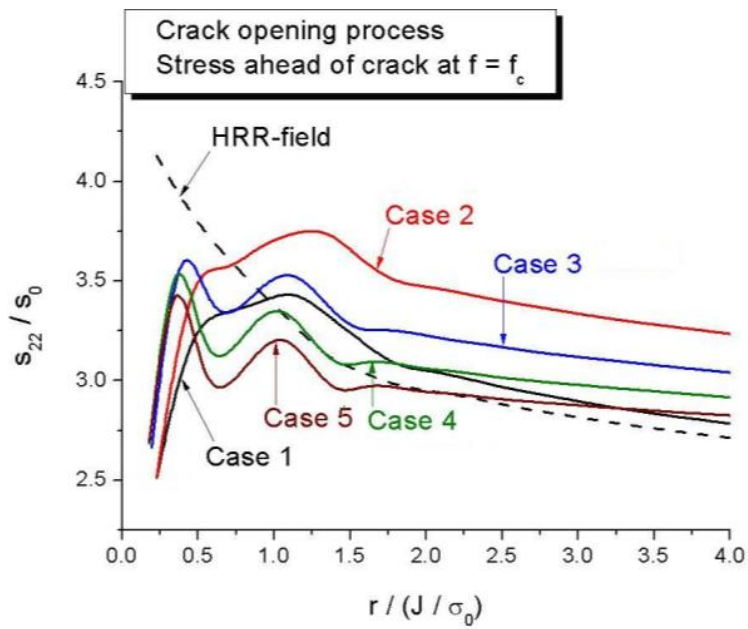

Figure 17 - Distribution of stresses normal to crack plane ahead of the crack at critical levels of crack driving forces with the GTN model.

\section{CONCLUSIONS}

The GTN model has been implemented via a sub-routine in a finite element code to assess the susceptibility of an enlarged CT specimen (x8), subject to residual stresses and various load histories, to ductile fracture initiation. A typical critical void volume fraction for fracture initiation was defined and used as the failure criterion. The results showed a significant detrimental effect to the global load carrying capacity of the specimen in the presence of a tensile residual stress field ahead of the crack. In some cases, subsequent global tensile overloads were applied that modified the residual stress field to various degrees depending on the magnitude of the overload. In the particular cases studied here, the size of the effect on the residual stress field scaled with the size of the overload, though scoping calculations suggest there is a saturation of the effect at overloads slightly bigger than the largest used here.

The modifications to the residual stress field resulted in increased load carrying capacity in the specimen relative to the case where no overload was applied and the tensile residual stress field remained unaltered. However, in all cases where residual stresses were present, the global load carrying capacity of the specimen was smaller than for a specimen containing no residual stress. This trend was replicated when global $J$-integral values were calculated from the global loaddisplacement behaviour, in accordance with the relevant testing standard. This is the behaviour that would be measured in equivalent physical tests.

Using the latest formulation of JEDI, an attempt has been made to calculate near-field $J$, i.e. local fracture toughness, and CTOD, to establish their usefulness as a fracture initiation criterion that capture load history effects. The results did not support the globally observed trends and it is shown that local $J$ values do not conform to the HRR field, suggesting that due to the material softening associated with the GTN model in highly damaged regions e.g. at the crack tip, the crack tip conditions are not adequately described by $J$.

\section{ACKNOWLEDGMENTS}

The authors gratefully acknowledge Rolls-Royce plc for their support of this research and Prof. Andrew Sherry for many valuable discussions around the themes presented here.

\section{REFERENCES}

[1] Gurson AL, "Continuum theory of ductile rupture by void nucleation and growth: part 1 - yield criteria and flow rules for porous ductile materials", J. Eng. Matl. Tech. 99, 2-15, 1977.

[2] Tvergaard V, "On localisation in ductile materials containing spherical voids”, Int. J. Fract. 18, 237-252, 1982.

[3] Tvergaard V, Needleman A, "Analysis of cup-cone fracture in a round tensile bar", Acta Metall. 32, 157-169, 1984.

[4] "R6 Revision 4, Assessment of the Integrity of Structure containing Defects", Bristish Energy Generation Ltd, Gloucester, UK, 2006.

[5] Beremin FM, "A local criterion for cleavage fracture of nuclear pressure vessel steels", Met Trans, 14A, 2277-2287, 1983.

[6] Beremin FM, "Effect of stress-triaxiality on the ductile tearing and the cleavage fracture of a mild-steel”, J. Mec. Appl. 4, 327-342, 1980.

[7] Rice JR, Tracey DM, "On the ductile enlargement of voids in triaxial stress fields”, J. Mech. Phys. Solids 17, 201-217, 1969.

[8]ABAQUS User's Manual, Dassault Systemes, 2007

[9] D W Beardsmore, M A Wilkes, A Shterenlikht, "An implementation of the Gurson-Tvergaard-Needleman plasticity model for ABAQUS Standard using a trust region method", Proceedings of the ASME Pressure Vessels and Piping Conference, Vancouver, 2006.

[10] Aravas N, "On the numerical integration of a class of pressuredependent plasticity models", Int. J. Num. Methods. Eng. 24, 13951416, 1987.

[11] A Shterenlikht and D. W. Beardsmore, "Numerical integration of GTN model for ABAQUS user material subroutine", Manchester University and Serco Assurance Report, 2005

[12] Rice JR, "A path independent integral and approximate analysis of strain concentration by notches and cracks", J. Appl. Mech. 35, 379-386, 1968.

[13] Aoki S, Kishimoto K, Sakata M, "Energy flux into process region in elastic-plastic fracture problems", Eng. Fract. Mech. 19, 827-836, 1984.

[14] Nikishov GP, Atluri SN, "Calculation of fracture mechanics parameters for an arbitrary three-dimensional crack by the "equivalent domain integral' method”, Int. J. Num. Methods Eng. 24, 1801-1821, 1987.

[15]D W Beardsmore and A H Sherry, "Allowance for residual stresses and material interfaces when calculating $\mathrm{J}$ in and close to welded joints", ASME Pressure Vessels and Piping, Vol. 464, pp. 11-21, 2003 [16] E1820-06 Standard Test Method for Measurement of Fracture Toughness, ASTM, 2006.

[17] "AGR Materials Data Handbook R66", British Energy Generation Ltd, Gloucester, UK, 2006. 
DRAFT

ANNEX A

PUT ANNEX TITLE HERE

Put text of Annex here 